Article

\title{
Novel Siloxane-Modified Epoxy Resins as Promising Encapsulant for LEDs
}

\author{
Chih-Hao Lin ${ }^{1}{ }^{\circledR}$, Wha-Tzong Whang ${ }^{1}$, Chun-Hua Chen ${ }^{1, *}$, Shu-Chen Huang ${ }^{2}$ and \\ Kai-Chi Chen ${ }^{2}$ \\ 1 Department of Materials Science and Engineering, National Chiao Tung University, 1001 University Rd., \\ Hsinchu 300, Taiwan; howardlin@itri.org.tw (C.-H.L.); wtwhang@mail.nctu.edu.tw (W.-T.W.) \\ 2 Material and Chemical Research Laboratories, Industrial Technology Research Institute, 195, Sec. 4, \\ Chung Hsing Rd., Chutung 31040, HsinChu, Taiwan; dogcoach432@gmail.com (S.-C.H.); \\ vickychen@itri.org.tw (K.-C.C.) \\ * Correspondence: chunhuachen@mail.nctu.edu.tw; Tel.: +886-3-5712121-55389
}

Received: 14 October 2019; Accepted: 18 December 2019; Published: 20 December 2019

\begin{abstract}
This study investigated a new category of transparent encapsulant materials for light-emitting diodes (LEDs). It comprised a phenyl group that contained siloxane-modified epoxy (SEP-Ph) hybridized with a cyclic tetrafunctional siloxane-modified epoxy (SEP-D4) with methylhexahydrophthalic anhydride (MHHPA) as a curing agent. The SEP-Ph/SEP-D4 = 0.5/0.5 (sample 3) and SEP-D4 (sample 4) could provide notably high optical transmittance (over $90 \%$ in the visible region), high-temperature discoloration resistance, low stress, and more crucially, noteworthy sulfurization resistance. The lumen flux retention of the SEP encapsulated surface mounted device LEDs remained between approximately $97 \%$ and $99 \%$ after a sulfurization test for $240 \mathrm{~h}$. The obtained comprehensive optical, mechanical, and sulfurization resistance proved the validity and uniqueness of the present design concept with complementary physical and chemical characteristics.
\end{abstract}

Keywords: siloxane-modified epoxy; crosslinking density; sulfurization resistance; surface mounted device LEDs; encapsulant

\section{Introduction}

Light-emitting diodes (LEDs) have become an essential light source because of their compact size, high efficiency, high brightness, low power consumption, and long operating lifetime. The performance of LEDs is greatly affected by the properties of their encapsulation materials, such as high optical transmittance, thermal- and photostability, low stress, and gas permeation resistance [1-6]. Transparent encapsulation materials are used to protect LED chips and can generally be divided into two main categories: epoxy resins [7,8] and silicone resins [9].

Transparent epoxy resins cured with anhydrides possess good optical clarity, strong adhesion, and high mechanical strength; however, their poor thermal- and photostability, as well as high thermal stress result in discoloration of and catastrophic damage to LED devices, which restricts their application. By contrast, silicone resins have excellent thermal- and photostability, and are thus usually applied in mid- to high-power LED packaging; however, their weak adhesion and high gas permeability, mainly originating from their highly flexible siloxane backbone, which allows for gas diffusion $[10,11]$, are crucial concerns for some applications.

A series of siloxane-modified epoxy resins have been extensively investigated with the aim of combining the merits of epoxy and silicone resins [12-18]. Morita et al. synthesized an epoxy siloxane monomer with a cycloaliphatic epoxy group at the terminal of the siloxane chain and demonstrated improved thermal- and photostability through curing with appropriate quantities 
of anhydride hardener and accelerator $[14,15]$. Huang et al. developed a series of cyclic silicone epoxies with various numbers of epoxy groups. By curing with aluminum acetylacetonate $\left(\mathrm{Al}(\mathrm{acac})_{3}\right)$ and diphenylsilanediol $\left(\mathrm{Ph}_{2} \mathrm{Si}(\mathrm{OH})_{2}\right)$, enhanced ultraviolet stability was achieved compared with an anhydride-cured cycloaliphatic epoxy [16]. Hue et al. prepared a transparent composition using the diglycidyl ether of bisphenol A and a phenylmethylsiloxane-modified epoxy (PMSE) hybrid resin. Curing with methylhexahydrophthalic anhydride (MHHPA) revealed that the addition of an appropriate amount of PMSE could effectively improve high-temperature thermal stability, dynamic mechanical stability, and performance of LEDs [18].

Currently, surface mounted device LEDs (SMD LEDs) are advancing and their packages are becoming smaller and thinner. This allows harmful contaminants in the atmosphere such as hydrogen sulfide $\left(\mathrm{H}_{2} \mathrm{~S}\right)$ to easily permeate an LED's package through its transparent encapsulation material. In this case, the bottom silver electrodes would darken because of the formation of silver sulfide, which would be accompanied by a significant decrease in the LED's light output. Although transparent epoxy-based encapsulants exhibit suitable gas barrier properties, the high thermal stress of epoxy resins that is generated during the soldering or temperature-cycling process would cause catastrophic damage. By contrast, silicone materials possess relatively low thermal stress compared with conventional epoxy resins, but their higher gas permeation properties would pose a problem for thin SMD LED packages, especially in outdoor applications.

Many research studies have been conducted to enhance the gas barrier properties of transparent polymers, one of which added nanoscale lamellar fillers with a large aspect ratio, such as clay or graphene, into the polymer matrix $[19,20]$. The addition of clay can alter and extend the gas molecule diffusion pathway; furthermore, the incorporation of graphene can effectively prevent gas molecules from permeating into the polymer matrix; however, the aggregation of nanoscale fillers can result in opacity, significantly reducing the optical transmittance of the polymer matrix. Moreover, the addition of clay can accelerate its rate of photooxidation [20]. The second option is to employ vapor deposition or coat a dense inorganic or organic material (e.g., $\mathrm{SiOx}, \mathrm{Al}_{2} \mathrm{O}_{3}$, or organic polysilazane) onto the surface of the polymer matrix. However, this approach requires special facilities (e.g., CVD and vacuum conditions) and complicated processes [21-23].

In this study, we designed a promising transparent material with compromised properties, namely high optical transmittance, high thermal stability, low modulus, and high sulfurization resistance, through blending the phenyl group-containing siloxane-modified epoxy (SEP-Ph) and cyclic tetrafunctional siloxane-modified epoxy (SEP-D4). The structure of SEP-Ph has multiple epoxy groups and flexible siloxane segments, which have the benefit of reducing the modulus without sacrificing the glass transition temperature $\left(T_{\mathrm{g}}\right)$. Moreover, the rigid structure of SEP-D4 with tetra epoxy groups could contribute thermal dimensional stability and high crosslinking density, and, more crucially, high sulfurization resistance should be obtained for transparent encapsulants.

\section{Materials and Methods}

\subsection{Materials}

Hydride-terminated 1,3,5,7-tetramethylcyclotetrasiloxane and tris(dibutylsulfide)rhodium trichloride were obtained from Gelest (Morrisville, PA, USA). The phenyl group-containing siloxane-modified epoxy (SEP-Ph, EEW = 670; see Figure 1) was provided by Grandtek Co. Ltd. (Hsinchu, Taiwan). Furthermore, 4-vinyl-1-cyclohexene-1,2-epoxy was purchased from Aldrich (St. Louis, MO, USA); N,N-dioctadecylmethylamine was supplied by Fluka (Tokyo, Japan); charcoal active powder was obtained from SHOWA (Saitama, Japan); methylhexahydrophthalic anhydride (MHHPA) was supplied by New Japan Chemical Co., Ltd. (Osaka, Japan); and the special amine curing accelerator U-CAT 18X was purchased from San-Apro (Kyoto, Japan). 


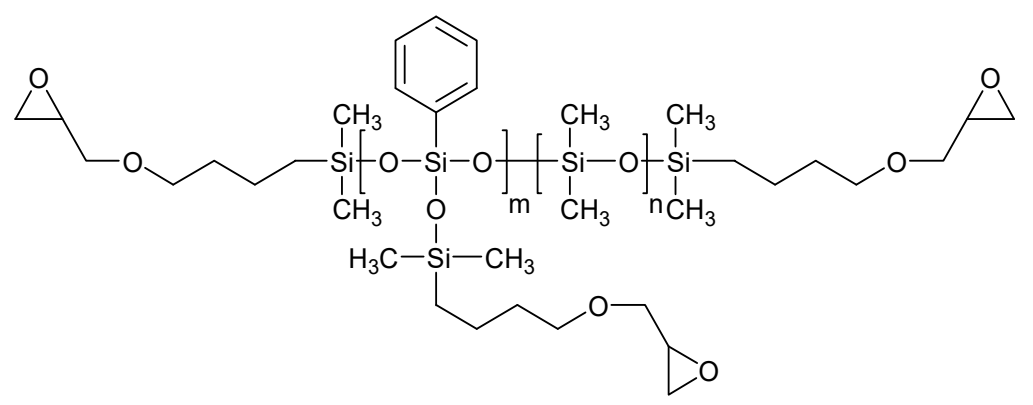

Figure 1. Structure of phenyl group-containing multi-functional siloxane-modified epoxy SEP-Ph.

\subsection{Synthesis of 1,3,5,7-Tetramethyl-1,3,5,7-Tetra[(3,4-Epoxycyclohexyl)Ethyl]-Cyclotetrasiloxane (SEP-D4)}

The synthesis of 1,3,5,7-tetramethyl-1,3,5,7-tetra[(3,4-epoxycyclohexyl)ethyl]-cyclotetrasiloxane (SEP-D4) was conducted according to the hydrosilylation reaction [24,25]. Scheme 1 illustrates the synthesis route. First, $50 \mathrm{~g}$ of 1,3,5,7-tetramethylcyclotetrasiloxane $(0.21 \mathrm{~mol})$ and $150 \mathrm{~mL}$ of toluene were added to a 1-L, three-necked, round-bottomed flask filled with high-purity nitrogen. Then, the mixture was heated to $100{ }^{\circ} \mathrm{C}$ and stirred for $20 \mathrm{~min}$. Next, $2.55 \mathrm{~g}$ of tris(dibutylsulfide)rhodium trichloride diluted solution ( $0.8 \mathrm{~g}$ of tris(dibutylsulfide)rhodium trichloride dissolved in $80 \mathrm{~g}$ of toluene) was added to the mixture before it was stirred for another $20 \mathrm{~min}$ at $100{ }^{\circ} \mathrm{C}$. Subsequently, $115 \mathrm{~g}$ of 4-vinyl-1-cyclohexene-1,2-epoxy $(0.84 \mathrm{~mol})$ was added dropwise into the reaction mixture; next, the reaction temperature was raised to $115{ }^{\circ} \mathrm{C}$ and the mixture was stirred for $72 \mathrm{~h}$. Fourier-transform infrared spectroscopy was used to monitor the reaction completely through the disappearance of $2150 \mathrm{~cm}^{-1}$ for $\mathrm{Si}-\mathrm{H}$ bonds. The hydrosilylation reaction was terminated by cooling the reaction mixture to room temperature and adding active carbon to deactivate the catalyst. After filtering the active carbon in the reaction mixture, the unreacted materials and solvent were removed through rotary evaporation at $80{ }^{\circ} \mathrm{C}$ to give the colorless transparent liquid products of 1,3,5,7-tetramethyl-1,3,5,7-tetra[(3,4-epoxycyclohexyl)ethyl]-cyclotetrasiloxane, ${ }^{1} \mathrm{H}$ NMR: $0.04 \mathrm{ppm}$ (s, $\left.\mathrm{CH}_{3}-\mathrm{Si}\right), 0.48 \mathrm{ppm}\left(\mathrm{m},-\mathrm{CH}_{2}-\mathrm{Si}\right), 0.17-2.18 \mathrm{ppm}$ (m, cyclohexyl group), $3.12 \mathrm{ppm}$ (m, epoxy group), and $\mathrm{EEW}=184$.

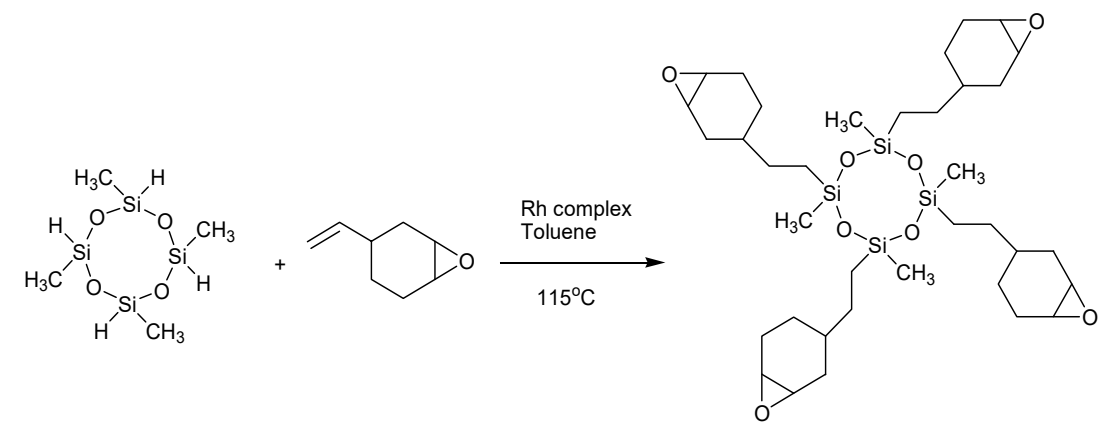

Scheme 1. Synthesis of 1,3,5,7-tetramethyl-1,3,5,7-tetra[(3,4-epoxycyclohexyl)ethyl]-cyclotetrasiloxane.

\subsection{Perpetration of Transparent SEP-Ph/SEP-D4/MHHPA Compositions}

Table 1 lists the mixing ratios by the equivalent weight of SEP-Ph/SEP-D4/MHHPA compositions. U-CAT 18X was used as a reaction accelerator (0.3 per hundred resin (phr) based on the total amount of SEP-Ph and SEP-D4) and mixed with MHHPA by stirring vigorously at room temperature until homogeneity was achieved. Then, SEP-Ph, SEP-D4, and the mixtures of SEP-Ph/SEP-D4 in different equivalent weight ratios were added to the abovementioned solution as well as stirred until homogeneous to form the final compositions. These compositions were then poured into a glass mold, degassed in a vacuum oven, and finally cured at $130^{\circ} \mathrm{C}$ for $1 \mathrm{~h}$ followed by $150{ }^{\circ} \mathrm{C}$ for another $2 \mathrm{~h}$. 
Table 1. Transparent siloxane-modified epoxy compositions.

\begin{tabular}{ccccc}
\hline Sample ID & Sample 1 & Sample 2 & Sample 3 & Sample 4 \\
\hline Compound & SEP-Ph & SEP-Ph/SEP-D4 $=0.8 / 0.2$ & SEP-Ph/SEP-D4 $=0.5 / 0.5$ & SEP-D4 \\
SEP-Ph & 1 & 0.8 & 0.5 & 0 \\
SEP-D4 & 0 & 0.2 & 0.5 & 1 \\
MHHPA & 1 & 1 & 1 & 1 \\
\hline
\end{tabular}

\subsection{Instrumentation}

${ }^{1} \mathrm{H}-\mathrm{NMR}$ analysis was performed on a NMR spectrometer (Varian $500 \mathrm{MHz}$; Agilent, Santa Clara, CA, USA) with $\mathrm{CDCl}_{3}$ as the solvent and TMS as a reference. Differential scanning calorimetry (DSC Q10; TA Instrument, New Castle, DE, USA) analysis was conducted under a nitrogen atmosphere. Approximately $10 \mathrm{mg}$ of the testing sample was sealed in an aluminum pan. The samples were heated from 40 to $300{ }^{\circ} \mathrm{C}$ at a rate of $10^{\circ} \mathrm{C} / \mathrm{min}$. The onset temperature, peak temperature, and enthalpy of the exothermic peak of the curing compositions were recorded. Modulated DSC (mDSC Q2000; TA Instrument, New Castle, DE, USA) analysis was conducted under a nitrogen atmosphere. Approximately $10 \mathrm{mg}$ of the testing sample was sealed in an aluminum pan. The sample was equilibrated at $-60^{\circ} \mathrm{C}$, modulated at $\pm 1.00^{\circ} \mathrm{C}$ every $60 \mathrm{~s}$ as well as isothermally for $5 \mathrm{~min}$, and then heated to $250^{\circ} \mathrm{C}$ at a heating rate of $5^{\circ} \mathrm{C} / \mathrm{min}$. The glass transition temperature $\left(T_{\mathrm{g}}\right)$ was determined by the inflection point of the reverse heat flow curve. Thermal degradation properties were measured using a TGA (TGA 7; Perkin Elmer, Waltham, MA, USA) from $30{ }^{\circ} \mathrm{C}$ to $800{ }^{\circ} \mathrm{C}$ at a heating rate of $10^{\circ} \mathrm{C} / \mathrm{min}$. Dynamic mechanical analysis (DMA Q800; TA Instrument, New Castle, DE, USA) was performed at a heating rate of $5{ }^{\circ} \mathrm{C} / \mathrm{min}$ from -100 to $280^{\circ} \mathrm{C}$ at a fixed frequency of $1 \mathrm{~Hz}$ in single cantilever mode. The dimensions of the test specimen were $17.5 \mathrm{~mm}(L) \times 12.8 \mathrm{~mm}(W) \times 3.2 \mathrm{~mm}(T)$. Optical transmittance from 350 to $800 \mathrm{~nm}$ was measured using UV/Vis spectrometer (Lambda 950; Perkin Elmer, Waltham, MA, USA) and the sample thickness was $2 \mathrm{~mm}$. Thermal mechanical analysis (TMA Q400; TA Instrument, New Castle, DE, USA) was conducted at a heating rate of $10^{\circ} \mathrm{C} / \mathrm{min}$ from $-50^{\circ} \mathrm{C}$ to $250{ }^{\circ} \mathrm{C}$. Optical properties of the LED were measured using an integrating sphere (ISP-250; Instrument Systems, Munich, Germany) with a driving current of $150 \mathrm{~mA}$.

\subsection{Encapsulation of SMD LEDs}

In this study, EMC3030 (Sander Electronics, Taipei, Taiwan) SMD LEDs bonded with a $350 \mathrm{~mA}$ blue LED chip were used for the optical-device testing vehicle. Before encapsulation, the lead frame was baked at $140{ }^{\circ} \mathrm{C}$ for $2 \mathrm{~h}$ to remove moisture, followed by the compositions being dispensed into the cavity of the EMC3030 SMD LED. The samples in this study were cured in a high-temperature oven with curing profiles of $130^{\circ} \mathrm{C}$ for $1 \mathrm{~h}$ and $150^{\circ} \mathrm{C}$ for $2 \mathrm{~h}$. The commercial silicone was cured with curing profiles of $100{ }^{\circ} \mathrm{C}$ for $1 \mathrm{~h}$ and $150^{\circ} \mathrm{C}$ for $5 \mathrm{~h}$. After encapsulation, the optical property of luminous flux was measured using the integrating sphere.

\subsection{Sulfurization Test of the Encapsulated SMD LEDs}

This study performed a sulfurization test on the SMD LEDs encapsulated by the transparent siloxane-modified epoxy compositions and commercial silicone to evaluate their sulfurization resistance. The encapsulated LEDs were attached to the wall side of a 100-mL glass sample flask; $0.2 \mathrm{~g}$ of sulfur powder was placed in the flask and closed, and then the flask was placed in a high-temperature oven at $70{ }^{\circ} \mathrm{C}$. Changes in color of the SMD LEDs' silver electrodes were observed during the sulfurization test period. Moreover, the light-output performance of the LED was recorded using the integrating sphere. 


\section{Results and Discussion}

\subsection{Curing Behavior and Miscibility of the Transparent Siloxane-Modified Epoxy Compositions}

The DSC analysis (see Figure 2a) revealed broad exothermic peaks for the four transparent siloxane-modified epoxy compositions. The exothermic onset temperatures were 132, 133, 122, and $128^{\circ} \mathrm{C}$, and the peak temperatures were $185,184,165$, and $190^{\circ} \mathrm{C}$ for samples $1,2,3$, and 4 , respectively. The curing behavior of samples 1 and 2 were similar. It might be due to the SEP-Ph/SEP-D4 were in a suitable balance of epoxy equivalent ratio of $0.5 / 0.5$, both the exothermic onset and peak temperatures decreased significantly, indicating superior reactivity compared with the others. Moreover, the curing heats of samples $1,2,3$, and 4 were $130,146,197$, and $311 \mathrm{~J} / \mathrm{g}$, respectively. The curing heat increased with the decreasing epoxy equivalent weight. In siloxane-modified epoxy, the larger epoxy equivalent indicated a greater amount of the dimethyl siloxane unit, which decreased the curing heat. The glass transition temperature $\left(T_{\mathrm{g}}\right)$ was determined using the inflection point of the reverse heat flow curve of mDSC, as displayed in Figure 2b. Samples 2 and 3 exhibited single inflection points, and the single $T_{\mathrm{g}}$ was evidence of the blending of SEP-Ph and SEP-D4 being miscible with no obvious phase separation. By contrast, the reverse heat flow curve of SEP-D4 did not exhibit any significant inflection, which was probably because of the highly rigid network restricting the molecular mobility.
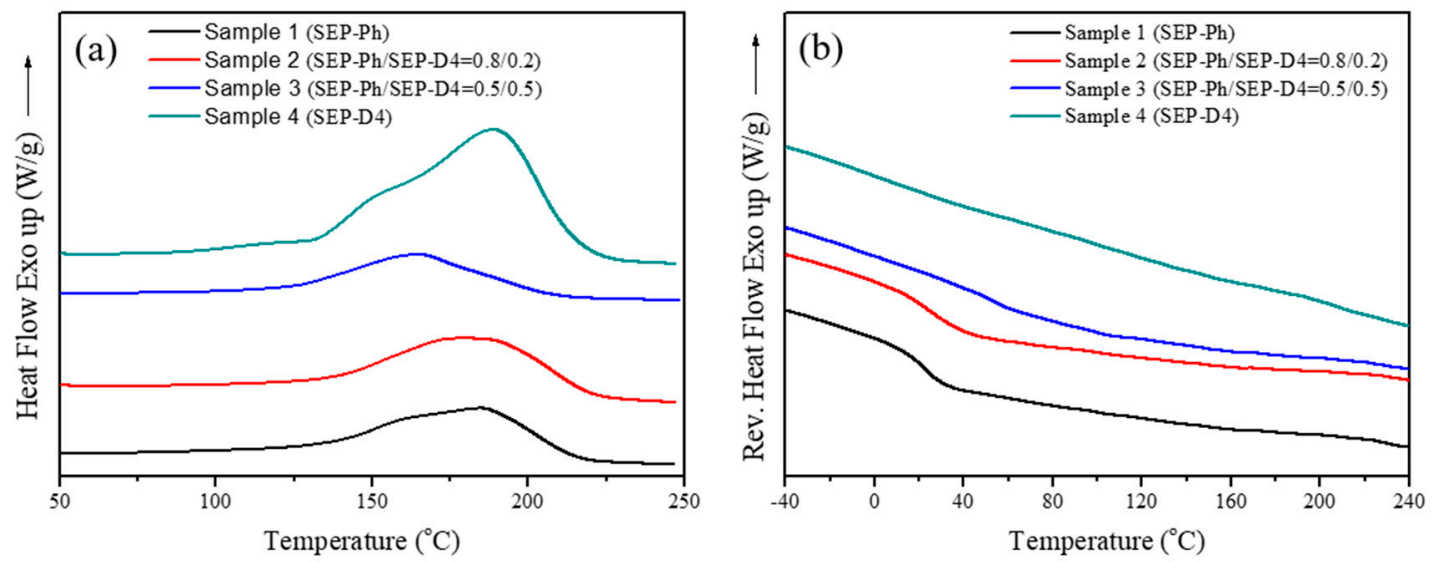

Figure 2. (a) Exothermic curves and (b) reverse heat flow curves of the transparent siloxane-modified epoxies.

\subsection{Optical Properties and Thermal Discoloration Resistance of the Transparent Siloxane-Modified Epoxy Compositions}

High optical transmittance and thermal discoloration resistance are basic requirements for transparent materials in optical-device applications. Figure 3a illustrates the optical transmittance of four cured transparent siloxane-modified epoxy compositions. The initial optical transmittance from 450 to $800 \mathrm{~nm}$ was over $88 \%$ with a sample thickness of $2 \mathrm{~mm}$, which suggested that materials with high optical transparency are required for LED encapsulation. Subsequently, thermal discoloration was evaluated by estimating the reduction in transmittance at $400 \mathrm{~nm}$, which was caused by the significant decline in transmittance in short-wavelength regions as discoloration occurred. Figure $3 b$ illustrates the variation in transmittance at $400 \mathrm{~nm}$ after $150{ }^{\circ} \mathrm{C}$ thermal aging of the transparent siloxane-modified epoxy compositions for 48,96, and 168 hours. The initial transmittance values at $400 \mathrm{~nm}$ of samples $1-4$ were $88 \%, 86 \%, 88 \%$, and $88 \%$, and decreased to $70 \%, 73 \%, 78 \%$, and $79 \%$ after thermal aging at $150{ }^{\circ} \mathrm{C}$ for 168 hours. Significant transmittance decay was observed at $400 \mathrm{~nm}$ in samples 1 and 2 (18\% and 13\%, respectively); by contrast, samples 3 and 4 exhibited relatively low transmittance decay at $400 \mathrm{~nm}$ of $10 \%$ and $9 \%$, respectively. As a result, samples 3 and 4 exhibited similar thermal discoloration resistance, which was superior to that of samples 1 and 2. Furthermore, the incorporation of SEP-D4 effectively enhanced the thermal discoloration resistance of SEP-Ph. The 
thermal discoloration resistance of the transparent siloxane-modified epoxy system in this study was similar to that in a previous study [26].
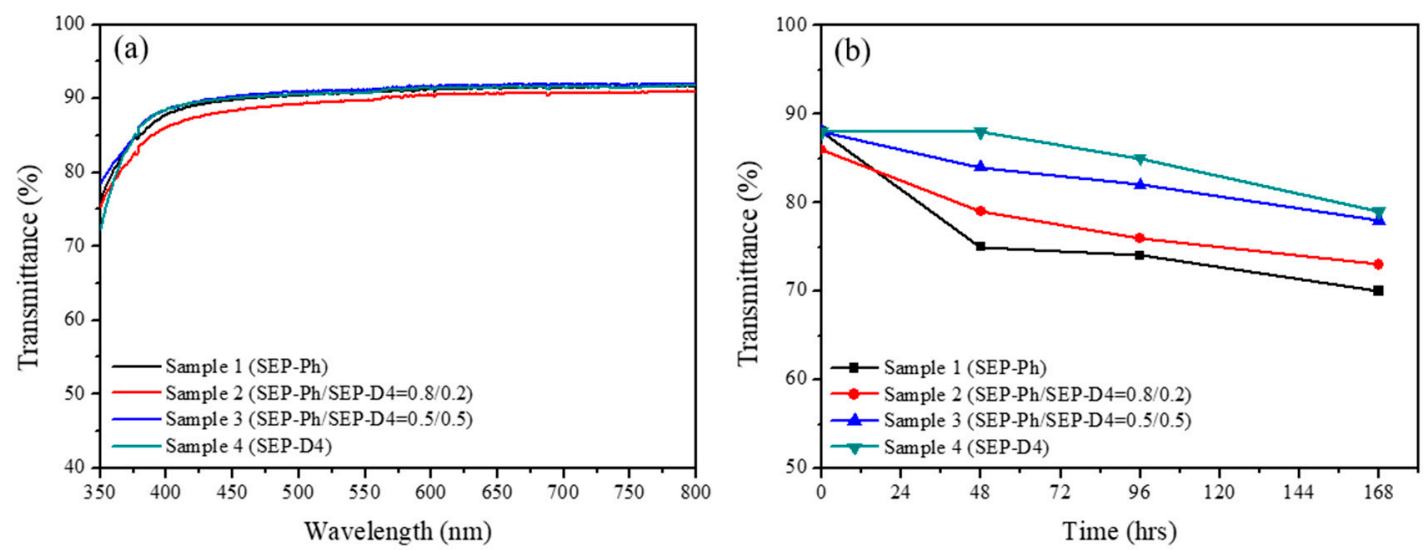

Figure 3. (a) UV/Vis spectra of the transparent siloxane-modified epoxies before thermal aging at $150{ }^{\circ} \mathrm{C}$, and (b) variation in transmittance at $400 \mathrm{~nm}$ as a function of time after thermal aging at $150{ }^{\circ} \mathrm{C}$.

\subsection{Thermal Decomposition and Mechanical Properties of the Transparent Siloxane-Modified Epoxy Compositions}

The thermal decomposition of samples 1, 2, 3, and 4 were studied using thermogravimetric analysis (TGA). Figure 4a shows the weight loss as a function of temperature. The onset decomposition temperatures were $376,367,353$, and $348^{\circ} \mathrm{C}$. The higher onset decomposition temperatures of samples 1-4 can ensure that no decomposition occurs under high-temperature processing conditions (e.g., during reflow process) in LED manufacturing.

In addition, the thermal dimensional stability and mechanical properties of transparent siloxane-modified epoxy compositions are critical for their application $[27,28]$. Therefore, the thermal dimensional stability of the compositions in this study was studied using thermal mechanical analysis (TMA). Figure $4 \mathrm{~b}$ presents dimension changes as a function of the temperature curve; the coefficients of thermal expansion (CTE) below $T_{\mathrm{g}}(\alpha 1)$ of samples $1-4$ were $101,94,89$, and $64 \mathrm{ppm} /{ }^{\circ} \mathrm{C}$, respectively. Sample 1 exhibited the highest $\alpha 1$ because of the flexible siloxane backbone of SEP-Ph, and it was reduced through incorporating a rigid structure of SEP-D4. A reason for this could be that introducing this rigid structure helped to restrict the segment motion of the transparent siloxane-modified epoxy, thereby lowing $\alpha 1$. This study noticed that the $\alpha 1$ values of samples $1-4$ were lower than that of the epoxy siloxane polymer that was prepared and investigated by Morita et al. [15]. Accordingly, superior thermal dimensional stability would be obtained.

Dynamic mechanical properties were evaluated using DMA analysis, which was conducted from -100 to $280^{\circ} \mathrm{C}$. The storage modulus is the elastic component of a material and is related to its stiffness. Figure $4 \mathrm{c}$ presents the storage modulus curve as a function of temperature. The storage modulus values of samples $1-4$ at $25^{\circ} \mathrm{C}$ was $97,230,1491$, and $2210 \mathrm{Mpa}$, respectively, which were lower than those of conventional cycloaliphatic epoxy and the silicone-epoxy resins studied by Yang et al. [29]. The storage modulus of samples 1-3 demonstrated an increasing trend with increasing quantities of SEP-D4, whereas sample 4 exhibited the highest storage modulus. This phenomenon could have originated from the rigid structure of SEP-D4 reinforcing and increasing the crosslinking density of transparent siloxane-modified epoxy systems.

The crosslinking densities of samples 1-4 were studied according to the storage modulus in a rubbery state. In general, a polymer material with a high crosslinking density usually exhibits a high storage modulus in the rubbery region. The crosslinking densities of samples 1-4 were calculated using the following equation $[30,31]$ and the results are summarized in Table 2:

$$
\rho=E^{\prime} / 3 R T
$$


where $\rho$ is the crosslinking density, $E^{\prime}$ is the storage modulus at temperature $T$ ( $T=T_{\mathrm{g}}+50 \mathrm{~K}$ and represents absolute temperature), and $R$ is the gas constant $\left(8.314 \mathrm{~J} \cdot \mathrm{K}^{-1} \cdot \mathrm{mol}^{-1}\right)$.

Table 2. Crosslinking densities of cured transparent siloxane-modified epoxy compositions.

\begin{tabular}{|c|c|c|c|}
\hline Sample & $T(\mathrm{~K})$ & $E^{\prime} @ T(\mathbf{M P a})$ & $\rho\left(10^{-3} \mathrm{~mol} / \mathrm{cm}^{3}\right)$ \\
\hline Sample 1 & 340.15 & 15.52 & 1.83 \\
\hline Sample 2 & 350.15 & 18.22 & 2.00 \\
\hline Sample 3 & 384.15 & 49.11 & 5.13 \\
\hline Sample 4 & 523.15 & 97.76 & 7.49 \\
\hline
\end{tabular}

The results indicated that as the quantity of SEP-D4 increased, the crosslinking density also increased, because of the increasing crosslinking point. Sample 4 had the highest crosslinking density among the prepared transparent siloxane-modified epoxy materials. A high crosslinking density is believed to be beneficial for reducing the free volume and network flexibility of siloxane-modified epoxy materials, and thus improving their sulfurization resistance [32-34].

$\operatorname{Tan} \delta$, which is defined as the ratio of loss modulus to storage modulus, is usually used to estimate the damping property of a material. Damping is the dissipation of energy in a material under cyclic loading. The glass transition temperature can also be determined using the peak value of $\tan \delta$ (see Figure 4d). In this study, the glass transition temperature of SEP-D4 was much higher than those of the transparent siloxane-modified epoxy compositions with different amounts of SEP-Ph. The $T_{\mathrm{g}}$ values of samples $1-4$ were $17,25,61$, and $200^{\circ} \mathrm{C}$, and their peak $\tan \delta$ values were $0.352,0.348,0.253$, and 0.183 , respectively. According to these results, this study concluded that increasing the amount of SEP-D4 results in a higher glass transition temperature, lower $\tan \delta$, and lower network flexibility, thereby, decreasing material's energy dissipation ability.
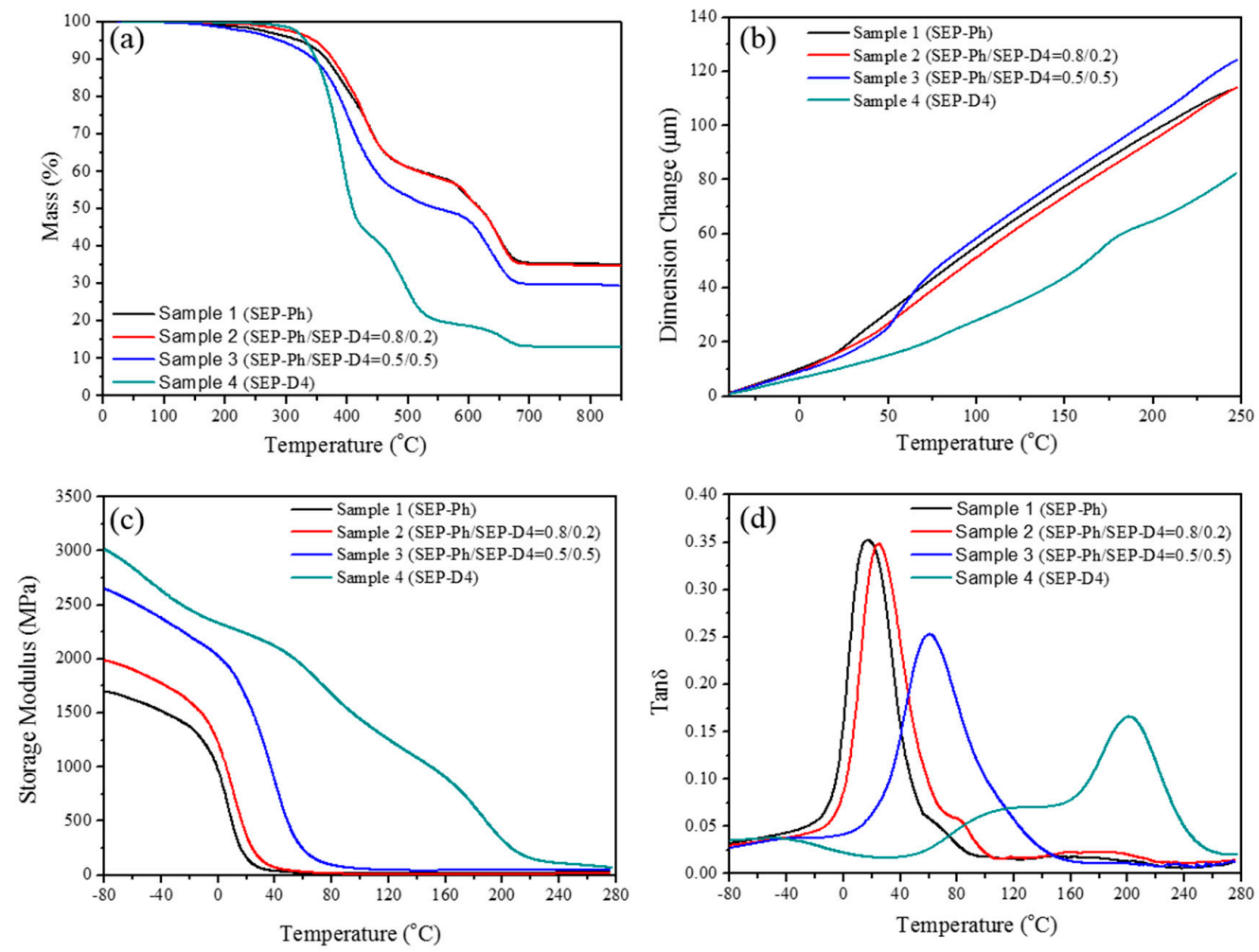

Figure 4. (a) Thermogravimetric analsis (TGA) curves and (b) Thermal mechanical analysis (TMA) curves of the transparent siloxane-modified epoxies. (c) Storage modulus and (d) $\tan \delta$ curves of the cured transparent siloxane-modified epoxies. 


\subsection{Sulfurization Resistance of the Transparent Siloxane-Modified Epoxy Compositions}

The sulfurization resistance of the four transparent siloxane-modified epoxy compositions was evaluated with a sulfurization test of the encapsulated EMC3030 SMD LEDs at $70{ }^{\circ} \mathrm{C}$. The results were compared with those of a commercial silicone encapsulant and are displayed in Figure 5 and Table 3. The initial average luminous flux values of the EMC3030 SMD LEDs encapsulated by samples 1-4 and commercial silicone were $6.6,6.6,6.6,6.8$, and $6.7 \mathrm{~lm}$, respectively. The commercial silicone exhibited poorer sulfurization resistance than the transparent siloxane-modified epoxy compositions; the average luminous flux retention of the EMC3030 SMD LEDs encapsulated by commercial silicone exhibited an obvious decrease to $73.1 \%$ after the sulfurization test for $48 \mathrm{~h}$, because the silver electrode of the LED was corroded by the permeating sulfur molecules and its surface darkened. Consequently, the partial light output from the LED chip was absorbed, resulting in luminous flux decay. By contrast, the sulfurization resistance of samples 1 and 2 was superior to that of the commercial silicone; furthermore, the average luminous flux retentions of samples 1 and 2 were $83.3 \%$ and $86.4 \%$, respectively, as the testing time was extended to $240 \mathrm{~h}$. Furthermore, the EMC3030 SMD LEDs encapsulated by samples 3 and 4 exhibited superior sulfurization resistance compared with samples 1 and 2 and the commercial silicone. Moreover, the average luminous flux retentions of samples 3 and 4 were $98.5 \%$ and $97.1 \%$, respectively, after the sulfurization test for $240 \mathrm{~h}$, and the silver electrode remained in its initial state. These results indicated that the sulfurization resistance of the prepared transparent siloxane-modified epoxy compositions was greatly improved through increasing the quantity of SEP-D4 in the compositions to an appropriate level.

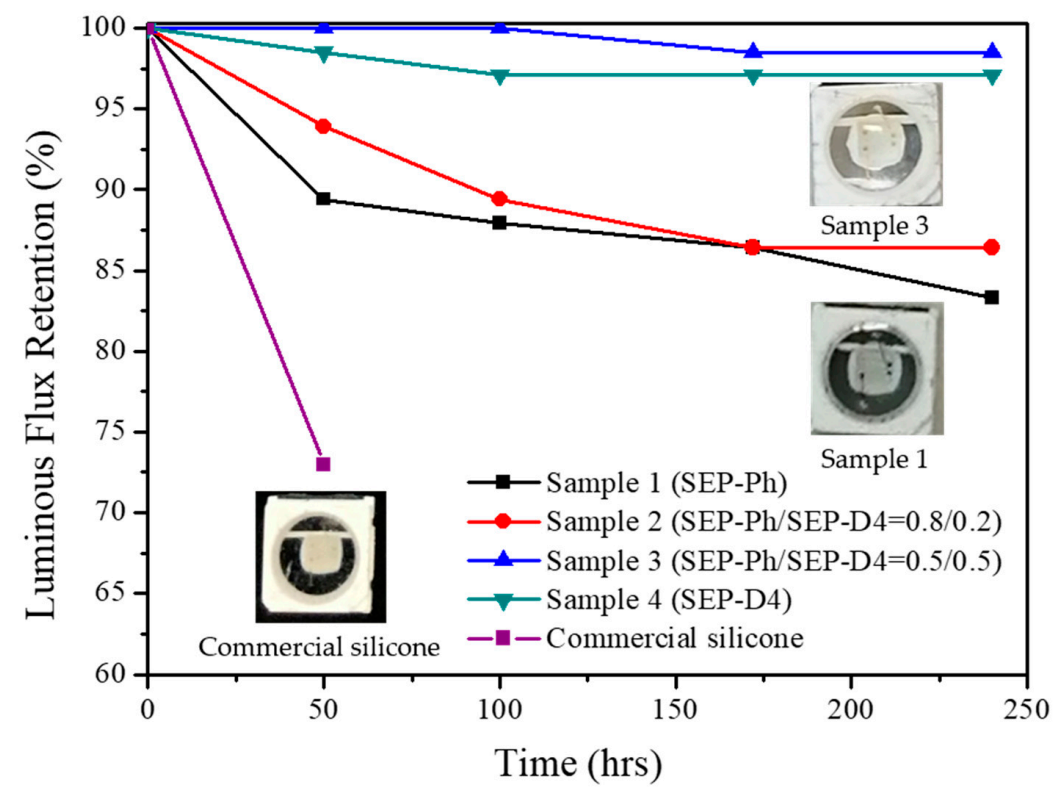

Figure 5. Luminous flux retention curve as a function of the sulfur test time of the prepared transparent siloxane-modified epoxies and commercial silicone.

Table 3. Optical properties of EMC3030 surface mounted device light-emitting diodes (SMD LEDs) before and after the sulfurization test.

\begin{tabular}{|c|c|c|c|}
\hline Sample & $\begin{array}{l}\text { Luminous Flux Before } \\
\text { Sulfur Test (lm) }\end{array}$ & $\begin{array}{l}\text { Luminous Flux After } \\
\text { Sulfur Test for } 240 \mathrm{~h}(\mathrm{~lm})\end{array}$ & $\begin{array}{c}\text { Luminous Flux Retention } \\
\text { Percentage }(\%)\end{array}$ \\
\hline Sample 1 & 6.6 & 5.5 & 83.3 \\
\hline Sample 2 & 6.6 & 5.7 & 86.4 \\
\hline Sample 3 & 6.6 & 6.5 & 98.5 \\
\hline Sample 4 & 6.8 & 6.6 & 97.1 \\
\hline Commercial silicone & 6.7 & $4.9 *$ & $73.1 *$ \\
\hline
\end{tabular}

* Sulfurization test conducted for $48 \mathrm{~h}$. 
In addition, the sulfurization resistance behaviors of the EMC3030 SMD LEDs encapsulated by samples 1-4 were found to be correlated with crosslinking density, and are illustrated in Figure 6. Samples 1 and 2 had relatively low crosslinking densities, which could reasonably explain their relatively low sulfurization resistance; by contrast, samples 3 and 4 possessed relatively high crosslinking densities, which demonstrated their promising sulfurization resistance.

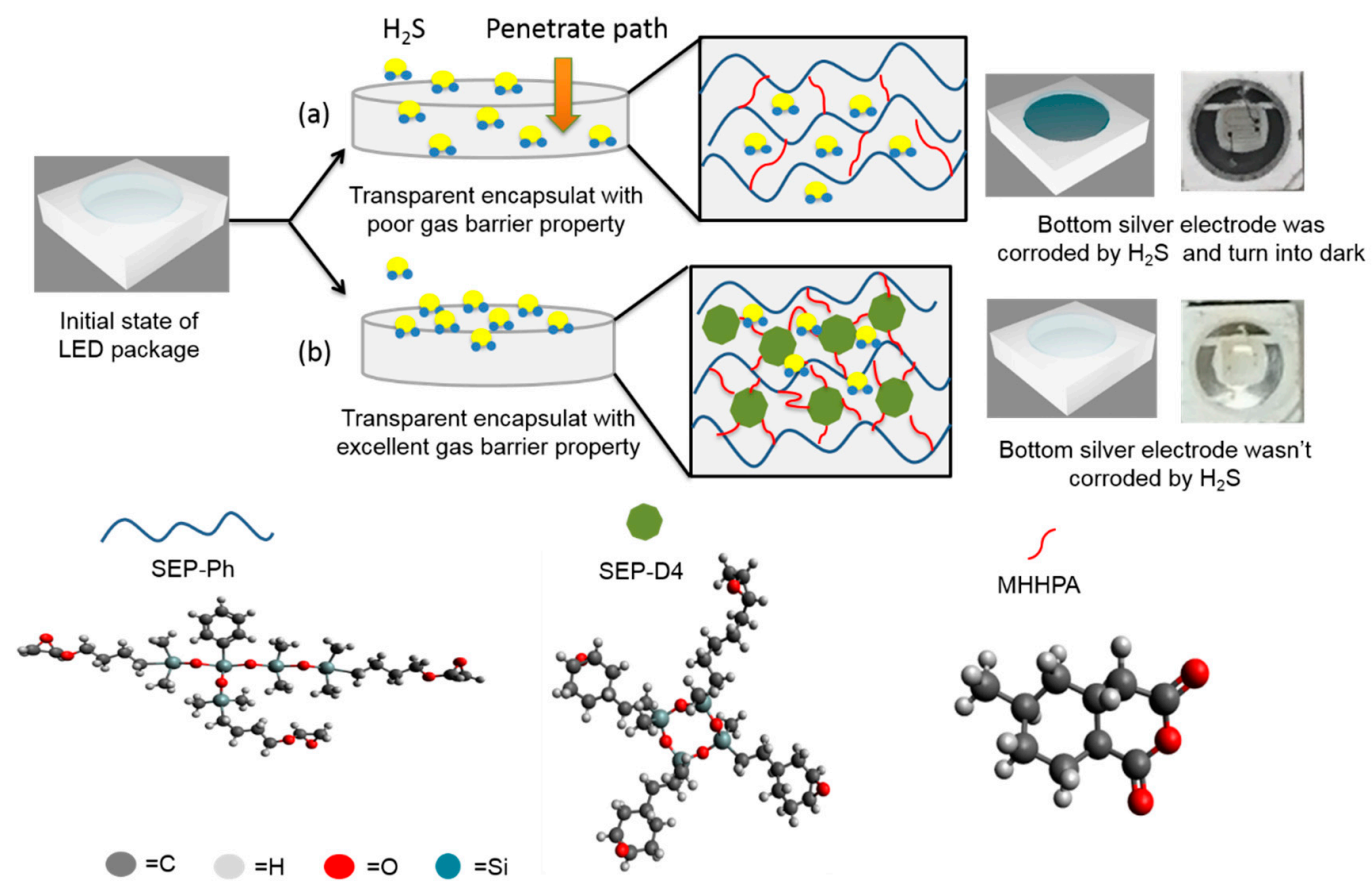

Figure 6. (a) Hydrogen sulfide $\left(\mathrm{H}_{2} \mathrm{~S}\right)$ could not only easily permeate into the phenyl group-containing siloxane-modified epoxy (SEP-Ph), but reacted with the bottom silver electrodes, which lead to the significant decay of the LED's light-output performance. (b) Schematic of the proposed key strategy for enhancing the sulfurization resistance of SEP-Ph through blending cyclic tetrafunctional siloxane-modified epoxy (SEP-D4), thereby increasing the crosslinking density of the siloxane-modified epoxy material.

Adding appropriate amounts of SEP-D4 into the SEP-Ph composition led to increased crosslinking density and reduced network flexibility. Therefore, acceptable sulfurization resistance could be obtained. Notably, after the LEDs were exposed to sulfur gas for $24 \mathrm{~h}$, those encapsulated with samples 3 and 4 exhibited higher flux retention than that encapsulated with only trifluoropropyl phenyl silicone rubber or even with an additional protective polysilazane top layer [21]. The much longer duration time of approximately $240 \mathrm{~h}$ provided strong evidence of the durability of the present siloxane-modified epoxy recipe.

\section{Conclusions}

In summary, this study investigated a siloxane-modified epoxy material with high transparency, good thermal discoloration resistance, low thermomechanical stress, and promising sulfurization resistance through incorporating SEP-D4 into SEP-Ph and an MHHPA curing agent composition. SEP-D4 exhibited a high capacity with SEP-Ph and MHHPA in various equivalent ratios. The results indicated that both samples 3 and 4 had high transmittance (approx. 90\%) in the visible light region, high thermal discoloration resistance (transmittance at $400 \mathrm{~nm}$ decayed by $10 \%$ and $9 \%$ after thermal aging at $150{ }^{\circ} \mathrm{C}$ for $168 \mathrm{~h}$ ). Furthermore, the lumen flux retention of the LED encapsulated by these compositions approached $97 \%-99 \%$ after a sulfurization test for $240 \mathrm{~h}$. The comprehensive properties of the transparent siloxane-modified epoxies of samples 3 and 4 demonstrated promising properties for LED package applications. 
Author Contributions: S.-C.H., K.-C.C., C.-H.L. conceived the original concept. C.-H.L. conducted experiments and the investigation as well as wrote the manuscript. W.-T.W. and C.-H.C. directed and revised the manuscript. All authors have read and agreed to the published version of the manuscript.

Funding: This research received no external funding.

Acknowledgments: The authors would like to express their appreciation for the technical support from Material and Chemical Research Laboratories, ITRI. This manuscript was edited by Wallace Academic Editing.

Conflicts of Interest: The authors declare no conflict of interest.

\section{References}

1. Nakamura, S.; Mukai, T.; Senoh, M. Candela-class high-brightness InGaN/AlGaN double-heterostructure blue-light-emitting diodes. Appl. Phys. Lett. 1994, 64, 1687-1689.

2. Yam, Y.K.; Hassan, Z. Innovative advances in LED technology. Microelectron. J. 2005, 36, 129-137. [CrossRef]

3. Pimputkar, S.; Speck, J.S.; DenBaars, S.P.; Nakamura, S. Prospects for LED lighting. Nat. Photonics 2009, 3 , 180-182. [CrossRef]

4. Chang, M.H.; Das, D.; Varde, P.V.; Pecht, M. Light emitting diodes reliability review. Microelectron. Reliab. 2012, 52, 762-782. [CrossRef]

5. Narendran, N.; Gu, Y.; Freyssinier, J.P.; Yu, H.; Deng, L. Solid-state lighting: Failure analysis of white LEDs. J. Cryst. Growth 2004, 268, 449-456. [CrossRef]

6. Zibold, A.; Dammann, M.; Schmidt, R.; Konstanzer, H.; Kunzer, M. Influence of air pollutants on the lifetime of LEDs and analysis of degradation effects. Microelectron. Reliab. 2017, 77, 566-570. [CrossRef]

7. Huang, J.C.; Chu, Y.P.; Wei, M.; Deanin, R.D. Comparison of epoxy resins for applications in light-emitting diodes. Adv. Polym. Technol. 2004, 23, 298-306. [CrossRef]

8. Morita, Y. Cationic polymerization of hydrogenated bisphenol-A glycidyl ether with cycloaliphatic epoxy resin and its thermal discoloration. J. Appl. Polym. Sci. 2005, 97, 1395-1400. [CrossRef]

9. Norris, A.W.; Bahadur, M.; Yoshitake, M. In Novel silicone materials for LED packaging. In Proceedings of the SPIE 5941, Fifth International Conference on Solid State Lighting, San Diego, CA, USA, 14 September 2005.

10. Ha, S.Y.; Park, H.B.; Lee, Y.M. Percolational effect of siloxane content in poly (amideimide siloxane) on the gas permeation behavior. Macromolecules 1999, 32, 2394-2396. [CrossRef]

11. George, S.C.; Thomas, S. Transport phenomena through polymeric systems. Prog. Polym. Sci. 2001, 26, 985-1017. [CrossRef]

12. Crivello, J.V.; Lee, J.L. The synthesis, characterization, and photoinitiated cationic polymerization of silicon-containing epoxy resins. J. Polym. Sci. Part A Polym. Chem. 1990, 28, 479-503. [CrossRef]

13. Falk, B.; Crivello, J.V. Synthesis of epoxy-functional microspheres by cationic suspension photopolymerization. Chem. Mater. 2004, 16, 5033-5041. [CrossRef]

14. Morita, Y. Curing of epoxy siloxane monomer with anhydride. J. Appl. Polym. Sci. 2005, 97, 946-951. [CrossRef]

15. Morita, Y.; Tajima, S.; Suzuki, H.; Sugino, H. Thermally initiated cationic polymerization and properties of epoxy siloxane. J. Appl. Polym. Sci. 2006, 100, 2010-2019. [CrossRef]

16. Huang, W.; Zhang, Y.; Yu, Y.; Yuan, Y.J. Studies on UV-stable silicone-epoxy resins. Appl. Polym. Sci. 2007, 104, 3954-3959. [CrossRef]

17. Yang, S.C.; Kim, J.S.; Jin, J.H.; Kwak, S.Y.; Bae, B.S. Thermal resistance of cycloaliphatic epoxy hybrimer based on sol-gel derived oligosiloxane for LED encapsulation. J. Appl. Polym. Sci. 2010, 117, 2140-2145. [CrossRef]

18. Hsu, C.W.; Ma, C.C.M.; Tan, C.S.; Li, H.T.; Huang, S.C.; Lee, T.M.; Tai, H. Effect of thermal aging on the optical, dynamic mechanical, and morphological properties of phenylmethylsiloxane-modified epoxy for use as an LED encapsulant. Mater. Chem. Phys. 2012, 134, 789-796. [CrossRef]

19. Lee, S.; Hong, J.Y.; Jang, J. Multifunctional graphene sheets embedded in silicone encapsulant for superior performance of light-emitting diodes. ACS Nano 2013, 7, 5784-5790. [CrossRef]

20. Topolniak, I.; Chapel, A.; Gaume, J.; Bussiere, P.O.; Chaderyon, G.; Gardette, J.L.; Therias, S. Applications of polymer nanocomposites as encapsulants for solar cells and LEDs: Impact of photodegradation on barrier and optical properties. Polym. Degrad. Stab. 2017, 145, 52-59. [CrossRef] 
21. Zhu, H.; Dai, Z.; Tu, W. Study on the preparation and performance of low gas permeability trifluoropropyl phenyl silicone rubber. RSC Adv. 2017, 7, 39739-39747. [CrossRef]

22. Leterrier, Y. Durability of nanosized oxygen-barrier coatings on polymers. Prog. Mater. Sci. 2003, 48, 1-55. [CrossRef]

23. Affinito, J.D.; Gross, M.E.; Coronado, C.A.; Graff, G.L.; Greenwell, I.N.; Martin, P.M. A new method for fabricating transparent barrier layers. Thin Solid Films 1996, 291, 63-67. [CrossRef]

24. Putzien, S.; Nyuken, O.; Kühn, F.E. Functionalized polysilalkylene siloxanes (polycarbosiloxanes) by hydrosilylation-Catalysis and synthesis. Prog. Polym. Sci. 2010, 35, 687-713. [CrossRef]

25. Ortiz, R.A.; Sangermano, M.; Bongiovanni, R.; Valdez, A.E.G.; Durate, L.B.; Saucedo, I.P.; Priola, A. Synthesis of hybrid methacrylate-silicone-cyclohexanepoxide monomers and the study of their UV induced polymerization. Prog. Org. Coat. 2006, 57, 159-164. [CrossRef]

26. Gao, N.; Liu, W.Q.; Yan, Z.L.; Wang, Z.F. Synthesis and properties of transparent cycloaliphatic epoxy-silicone resins for opto-electronic devices packaging. Opt. Mater. 2013, 35, 567-575. [CrossRef]

27. Rimdust, R.; Ishida, H. Development of new class of electronic packaging materials based on ternary systems of benzoxazine, epoxy, and phenolic resins. Polymer 2000, 41, 7941-7949. [CrossRef]

28. Hu, J.; Yang, L.; Shin, M.W. Mechanism and thermal effect of delamination in light-emitting diode packages. Microelectron. J. 2007, 38, 157-163. [CrossRef]

29. Yang, X.; Huang, W.; Yu, Y. Synthesis, characterization, and properties of silicone-epoxy resins. J. Appl. Polym. Sci. 2011, 120, 1216-1224. [CrossRef]

30. Park, S.J.; Jin, F.L. Thermal stabilities and dynamic mechanical properties of sulfone-containing epoxy resin cured with anhydride. Polym. Degrad. Stab. 2004, 86, 515-520. [CrossRef]

31. Liu, W.S.; Wang, Z.G.; Chen, Z.; Li, J.F. Synthesis and properties of two novel silicon-containing cycloaliphatic epoxy resins for electronic packaging application. Polym. Adv. Technol. 2012, 23, 367-374. [CrossRef]

32. Srithawatpong, R.; Peng, Z.L.; Olson, B.G.; Jamieson, A.M.; Simha, R.; McGervey, J.D.; Maier, T.R.; Halasa, A.F.; Ishida, H. Positron annihilation lifetime studies of changes in free volume on cross-linking cis-polyisoprene, high-vinyl polybutadiene, and their miscible blends. J. Polym. Sci. Part B Polym. Phys. 1999, 37, 2754-2770. [CrossRef]

33. Liu, Y.; Wang, R.; Chung, T.S. Chemical cross-linking modification of polyimide membranes for gas separation. J. Membr. Sci. 2001, 189, 231-239. [CrossRef]

34. Tin, P.S.; Chung, T.S.; Liu, Y.; Wang, R.; Liu, S.L.; Pramod, K.P. Effects of cross-linking modification on gas separation performance of Matrimid membranes. J. Membr. Sci. 2003, 225, 77-90. [CrossRef] 